\title{
Sobre a importância do belo para \\ a verdade hermenêutica do ser
}

\section{On the importance of the beautiful to the hermeneutical truth of the being}

DOI: http://dx.doi.org/10.12957/ek.2015.14878

Mndo. Danton Guilherme Oestreich

dantonoestreich@gmail.com

CAPES/Unisinos

$\mathrm{O}$ artigo procura elucidar que uma leitura atenta do conceito de belo em Verdade e Método implica em três consequências essenciais: sua aproximação com a noção de verdade preconizada pela hermenêutica, sua importância para a autocompreensão, e que esta importância se afirma no ethos próprio de uma racionalidade existencial. Para isso, mostra como Gadamer assume perspectivas próprias em relação ao pensamento sobre a arte e a hermenêutica de Heidegger, e analisa a sua famosa crítica ao juízo estético de Kant - que são dois pontos fundamentais para a elucidação do conceito de belo em Verdade e Método. Assim, esta elucidação visa mostrar que a noção de verdade acaba sendo aprofundada e enriquecida em vista da sua relação com o belo, e acaba sugerindo que as considerações hermenêuticas abertas por Gadamer permitem ultrapassar a exposição meramente ontológica da obra de arte, quando se tem em vista o aspecto universal da hermenêutica.

PALAVRAS-CHAVE belo . hermenêutica .verdade

This article aims to clarify that a careful reading of the concept of beautiful in Truth and Method implies three main consequences: its approach to the notion of truth advocated by hermeneutics, its importance to the self-understanding, and that this importance is stated in the very ethos of an existential rationality. For this purpose, it shows how Gadamer takes own prospects in relation of Heidegger's thinking about art and hermeneutics, and analyses Gadamer's famous critique of Kant's aesthetic judgment - which are two key points to elucidate the concept of beautiful in Truth and Method. Thus, this elucidation aims to show that, in view of its relationship with the beautiful, the notion of truth turns out to be deepened and enriched, and ends up by suggesting that is possible to exceed the merely ontological presentation of work of art when the universal aspect of hermeneutics, opened by Gadamer, is put on consideration. 


\section{Introdução}

A primeira parte de Verdade e Método trata da restituição de um sentido da verdade realizada através da experiência que a arte oferece à compreensão humana, colocando como uma das questões essenciais para o todo da obra o problema das relações entre a arte, o belo e a verdade. Assumindo um viés hermenêutico, Gadamer parece dar prosseguimento ao pensamento sobre verdade e arte que é encontrado em Heidegger, onde o conceito de belo aparece ligado à verdade como aletheia, pois, para este último, a beleza seria "um modo como a verdade vigora enquanto desvelamento" (HEIDEGGER, 2010, p. 141). Todavia, ao tratar da questão da verdade por via da hermenêutica, Gadamer parece apresentar, ao final de Verdade e Método, relações mais amplas que visam o reconhecimento da importância do conceito de belo, recordando sua antiga natureza metafísica, para a própria dimensão da autocompreensão que se dá através da linguagem. Na verdade, é em função desta perspectiva que a sua investigação assume um elo fundamental com a Crítica da Faculdade do Juízo, que teria possivelmente produzido uma "subjetivação" da estética. A crítica de Gadamer sobre esta última questão fundamenta-se no fato de que os conceitos centrais da tradição humanista, que dariam aporte para uma legitimação própria às humanidades, são reunidos por Kant sem a consideração do significado social e comunitário que a eles seria imanente e que, consequentemente, permitiria o reconhecimento de um sentido de verdade relativo à tradição. A exemplo disto, se na função transcendental que Kant atribui ao gosto não lhe interessa de forma alguma o seu conteúdo, na dimensão social deste conceito a questão do seu conteúdo é determinante e leva a reconhecer que "o belo na natureza e na arte terá que ser completado pelo amplo oceano do belo que se alastra na realidade ética do homem" (GADAMER, 2012, p. 78/GW1, 43-44). Neste sentido, segue a hipótese de que a retomada do conceito de belo ao final de Verdade e Método não é simplesmente marginal ao seu desenvolvimento, pois, sendo o compreender e o interpretar, mediados pela linguagem e pela verdade da tradição, algo que pertence ao todo da experiência do homem no mundo, a determinação daquilo que é belo neste horizonte não escapa à uma crítica que pretende ser correta em sua avaliação com respeito à consciência ética que nos constitui. Desta forma, este artigo tem por objetivos elucidar a possibilidade de aproximação da noção de verdade com o conceito de belo no horizonte hermenêutico; o porquê da importância do belo para a autocompreensão; e de como essa importância se afirma no ethos próprio à uma racionalidade existencial. 
Para tanto, serão apresentadas no primeiro capítulo algumas das influências e das diferenças que pautam a relação filosófica de Gadamer com Heidegger, em relação aos seus pensamentos sobre a arte e a hermenêutica, em função de explicitar um horizonte prévio no qual a crítica de Gadamer à estética está baseada. Abordarei a crítica de Gadamer ao juízo estético de Kant no segundo capítulo, mostrando que a sua contraposição ao conceito de "jogo livre" quer negar que o belo possa ser simplesmente autônomo de qualquer questão de conteúdo. E no terceiro capítulo, sob a luz das considerações anteriores, apresento o porquê da importância dos conceitos de verdade e belo serem considerados de maneira complementar na hermenêutica. Ao final, sugiro que a própria noção de verdade é aprofundada e enriquecida em vista da sua relação com o belo, como também a experiência da arte prova ser uma fonte inestimável de autocompreensão ética diante da existência. Quero sugerir assim, que, se o pensamento sobre a arte na primeira parte de Verdade e Método se limita à apresentação de uma ontologia da obra de arte que está em função de "liberar a questão da verdade através da experiência da arte", quando vista no todo da obra, o pensamento sobre a arte por via da hermenêutica pode ser mais amplo ao reconhecer a possível experiência de compreensão ética da existência através da arte.

\section{O sentido da verdade e a posição do belo em Verdade e Método}

A necessidade de falar em uma restituição de um sentido da verdade é porque "desde a formulação clássica dos princípios de certeza de Descartes o verdadeiro ethos da ciência moderna passou a ser o fato de que ela só admite como condição satisfatória de verdade aquilo que satisfaz o ideal de certeza" (GADAMER, 2002, p. 62/GW2, 48). No entanto, é claro que considerar a noção de verdade em toda a extensão da sua experiência na existência faz esta condição de certeza se tornar um tanto limitada para o seu real dimensionamento na vida humana, sendo justamente neste contexto que a arte ganha toda importância para o pensamento de uma noção de verdade que está além de um conhecimento baseado na certeza. Para Gadamer

a enunciação da arte como a enunciação dos grandes filósofos denotava ainda mais uma aspiração à verdade, confusa e inevitável, que não se podia neutralizar 
com nenhuma "história do problema" nem se deixava submeter às leis da rígida cientificidade e do progresso metodológico. Esse sentimento foi caracterizado então na Alemanha como "existencial", sob a influência de uma reapropriação de Kierkegaard. Interessava uma verdade que não fosse devida tanto a alguns enunciados ou conhecimentos gerais, mas à imediatez das próprias vivências e a intransferibilidade da própria existência. (GADAMER, 2002, p. 548/GW2, 482)

Em relação à arte este pensamento parece ser caracterizado por um ponto comum, a saber: a crítica àquilo que, no caso de Gadamer, é chamado de "consciência estética”. Segundo Sallis (2007), este já é um aspecto que $A$ origem $d a$ obra de arte quer evidenciar, pois Heidegger, ao defender que a estética acaba reduzindo a experiência da obra de arte ao modo de percepção chamado de vivência (Erlebnis), ao toma-la como um simples objeto da sensação (aisthesis), já expõe a característica fundamental de abstração que percorre este modo de comportamento estético diante da arte. $\mathrm{Na}$ abordagem de cunho mais histórico que Gadamer realiza em relação a esta abstração do comportamento estético, importa mostrar que a subjetivação da estética tem a sua origem na separação que é realizada na Crítica da Faculdade do Juízo entre o juízo de gosto e o conhecimento de objetos, pois "na sequência da subjetivação da estética, a orientação da arte para a verdade é interrompida, pelo menos na medida em que a verdade é tomada para ser estritamente correlativa ao conhecimento" (SALLIS, 2007, p. 47). Na tensão destes dois pólos - o estético e o ontológico - Gadamer torna produtivo o seu pensamento sobre a arte e dá abertura às suas questões hermenêuticas; é esta tensão que irei abordar progressivamente, buscando explicitar que o sentido da presença do conceito de belo não é meramente marginal ao propósito de Verdade e Método.

$\mathrm{O}$ que vem a interessar e caracterizar grandemente o estudo de Heidegger sobre a arte é a retomada de uma aproximação original do conceito de verdade com a arte - Gadamer mesmo reconhece que este "estudo de Heidegger não se limita a dar uma descrição apropriada do ser da obra de arte. É muito mais o seu desejo filosófico central de conceber o ser mesmo como um acontecer da verdade que se respalda nessa análise" (GADAMER, 2007, p. 75). Enquanto tratada como "desvelamento", que está ligado ao sentido da aletheia grega, esta verdade é anterior àquela verdade que habitualmente se considera, na filosofia, enquanto um tipo de adequação; pois "existe uma condição anterior que pos- 
sibilita a enunciação de proposições e juízos e a sua comparação com o estado de coisas do mundo" (SHIMABUKURO, 2014, p. 88) e que também permite pensar o ser em sua essência, de modo ontológico. Aquilo que traz à frente a experiência do ser é experimentado como o desvelar de algo que permanecia velado até então, sendo neste sentido que o ser é compreendido como um acontecer da verdade. Na discussão promovida por Heidegger para esta noção de verdade, pelo menos enquanto associada à arte, o conceito de belo também está apresentado e destinado a ser pensado junto à esta verdade. Apesar de num primeiro momento Heidegger colocar ressalvas - dizendo que "a essência da arte seria esta: o pôr-se em obra da verdade do sendo. Mas, até agora a arte só tinha a ver com o belo e a beleza e não com a verdade" (HEIDEGGER, 2010, p. 87) - nota-se o verdadeiro sentido da relação do belo com a verdade a partir de outra consideração sua, que diz: "o aparecer brilhante, disposto na obra, é o belo. A beleza é um modo como a verdade vigora enquanto desvelamento" (HEIDEGGER, 2010, p. 141). No Posfácio de "A origem da obra de arte" a relação entre a verdade e a beleza está posta claramente, mostrando que é a verdade que deve "anteceder" ou ser "condição" da beleza na arte; vejamos:

A verdade, da qual aqui se fala, não coincide com a que se conhece sob este nome. E ela se atribui ao conhecimento e à ciência como uma qualidade para diferenciar dela o belo e o bom, que valem como os nomes para os valores dos procedimentos não teóricos. A verdade é o desvelamento do sendo enquanto sendo. A verdade é a verdade do ser. A beleza não aparece junto desta verdade. Quando a verdade se põe na obra, ela aparece. O aparecer é - como este ser da verdade na obra e como obra - a beleza. Assim, o belo pertence ao acontecer-se apropriante da verdade. Não é somente relativo ao gosto e pura e simplesmente como objeto dele. O belo reside na forma, mas apenas pelo fato de que a forma um dia se iluminou a partir do ser como a entidade do sendo. (HEIDEGGER, 2010, p. 207)

A proximidade da consideração de Heidegger com o próprio propósito que foi lançado para a investigação de Verdade e Método é evidente, afinal, Gadamer entende que é a partir da experiência da arte que toda a amplidão da 
questão da verdade, que está para além da requerida condição de adequação e certeza do modelo científico, é de fato liberada. Mas, se Gadamer procura estabelecer a sua investigação por via da hermenêutica, instituindo-a de uma dimensão de universalidade diante do fenômeno da compreensão, parece legítimo indagar pelas relações que possivelmente são sugeridas entre a noção de verdade e o conceito de belo para a autocompreensão que se dá através da linguagem. De modo mais específico, considerar isto é perceber que a verdade na hermenêutica filosófica encontra o seu sentido através da linguagem que, para Gadamer, reúne de um modo original o eu e o mundo, e perceber como o conceito de belo se aplica neste caso.

O conceito de belo pode passar por despercebido pelo uso pouco recorrente durante toda a primeira parte de Verdade e Método, que está a tratar da arte, se não tivermos em vista o seu retorno ao final da obra, desta vez de um modo bastante enfático e paralelo a discussão da verdade. Gadamer inicia a seção final do livro - "O aspecto universal da hermenêutica" - dizendo que "nossas reflexões se orientaram pela ideia de que a linguagem é um meio em que se reúnem o eu e o mundo, ou melhor, em que ambos aparecem em sua unidade originária" (GADAMER, 2012, p. 612/GW1, 478). Nesse contexto, "a linguagem possui uma estrutura especulativa, que não consiste em ser cópia de algo dado de modo fixo, mas num vir-à-fala, onde se enuncia um todo de sentido" (GADAMER, 2012, p. 612/GW1, 478) e, sendo assim, "o que vem à fala é, naturalmente, algo diferente da própria palavra falada" (GADAMER, 2012, p. 613/GW1, 479). É evidente que este "algo que vem à fala" tem por condição essencial a abertura e o desvelamento do ser hermenêutico - o que quer dizer, da compreensão pela linguagem - que ocorre a partir de um horizonte de sentido que serve como espaço de jogo para a experiência que o caracteriza. Por sua vez, o todo de sentido que é enunciado é o que realmente importa para a compreensão de seu horizonte. Vale especificar:

O horizonte é uma abertura limitada que, por conseguinte, muda assim que se muda de ponto de vista. Um horizonte de sentido, que é uma faixa contínua de mudança da existência linguística, é um todo na medida em que ele pode dar a si mesmo juntamente com a infinidade do não-dito. Nesta infinidade, o horizonte de sentido é infinitamente variável, infinitamente diverso, sem perder a sua contínua determinidade mutável. (FIGAL, 2002, p. 120). 
Ao falar da verdade que acontece a partir de um horizonte de sentido compreendido como linguagem, se fala de uma verdade que importa à nossa experiência finita de existência. É uma verdade especificamente humana aquela com a qual a hermenêutica se ocupa, verdade que tem por base "o modo como experimentamos uns aos outros, como experimentamos as tradições históricas, as ocorrências naturais de nossa existência e de nosso mundo" (GADAMER, 2012, p. 32). Assim, se a hermenêutica pretende ter um aspecto universal, este é apenas enquanto referente aos problemas que constituem a experiência de compreensão da nossa humanidade e de tudo aquilo que a ela é referente. Desta forma, a hermenêutica não está aí para refutar o conhecimento científico, mas para permitir o acesso às questões que a ciência não alcança.

Em meio desta discussão do aspecto universal da hermenêutica o conceito de belo é retomado. Gadamer assinala que apesar deste conceito ter sido reduzido a um problema da estética durante o século XVIII e posteriormente eliminado do centro da mesma, ele "foi antes um conceito metafísico universal e dentro da metafísica, isto é, da teoria geral do ser, exerceu uma função que de modo algum se restringia ao estético" (GADAMER, 2012, p. 615/GW1, 481). Essa aproximação ao conceito de belo se deve ao cunho ontológico que Gadamer dá ao seu questionamento hermenêutico, que - para a discussão da compreensão e da verdade - tem a ganhar com uma característica pontual da origem metafísica daquele conceito. Em Platão, por exemplo, apesar da relação muito próxima entre o belo e o bem, há o predomínio do belo: "porque pode ser mais facilmente apreendido, o belo se distingue do bem, que é o completamente inapreensível. Ele tem por essência a característica de aparecer. Na busca do bem, o que se mostra é o belo" (GADAMER, 2012, p. 620/GW1, 484). É esta peculiar característica do belo de "aparecer" no mundo e se fazer presente que interessa a Gadamer; pois, nesta característica ele pode ser considerado como análogo ao acontecer da compreensão que é capaz de sustentar a si mesmo em uma dada situação, que apresenta um horizonte de sentido, e que também é reconhecida como uma "iluminação" do ser. Assim como Heidegger, também Gadamer descreve a essência do belo como um "aparecer brilhante"; mas ao pensar que a experiência da beleza está além da estética e mesmo da arte, determinando-a como algo exemplar para o fenômeno da compreensão, então a desenvoltura da discussão hermenêutica sobre a verdade já não pode mais ser desvinculada de uma caracterização que é idêntica ao modo de ser do belo. Pois, se Gadamer diz que "tal como o belo é uma espécie de experiência que sobressai e se destaca como um encantamento ou uma aventura no conjunto de nossa experiência, tam- 
bém o evidente tem sempre algo de surpreendente, como o surgimento de uma nova luz que torna mais amplo o campo do que entra em consideração" (GADAMER, 2012, p. 625/GW1, 489), a experiência de verdade da qual Gadamer fala tem que ser, em certa medida, paralela à experiência do belo em todos os casos. Por outro lado, se a linguagem é um meio onde estão reunidos o eu e o mundo em sua unidade originária - o que quer dizer também que ela é algo que torna possível a nossa autocompreensão - e se o belo reside numa estreita relação com a compreensão, então, o belo deve ter algo a dizer à autocompreensão.

A partir destas considerações começa a se tornar perceptível uma possível diferença crucial no pensamento sobre a verdade e o belo de Gadamer e Heidegger - se no pensamento de Heidegger o belo assume ligação com a verdade mas não volta-se para qualquer questão ética, desde que Verdade e Método seja considerado em seu todo, é necessário admitir que Gadamer sugere um certo comprometimento com esta questão - e é com este discernimento que a primeira parte da obra pode ser lida de modo mais abrangente e compreensivo. A exemplo disto, quando Gadamer estabelece um primeiro posicionamento sobre o fundamento da perspectiva hermenêutica, em relação a arte, já está anunciada uma perspectiva ética no cerne do próprio problema - sendo que não é a Heidegger a quem é feita referência, mas sim a Kierkegaard - Gadamer diz:

\begin{abstract}
Sua teoria do estágio estético da existência foi projetada partindo da perspectiva do ético, a quem se tornou patente a impossibilidade de salvação e insustentabilidade de uma existência na pura imediatez e descontinuidade. Por isso, a seu ensaio crítico possui um significado fundamental, pois a crítica à consciência estética apresentada aqui revela tão nitidamente as contradições internas da existência estética que esta é obrigada a ir além de si mesma. (GADAMER, 2012, p. 147/GW1, 101)
\end{abstract}

A citação explícita a Kierkegaard, neste ponto, não deve ser compreendida apenas pelo sentido histórico de que este tenha sido o primeiro a criticar a noção de "consciência estética", mas como um próprio propósito em que Gadamer se espelha. Na necessidade da continuidade da existência, a compreensão não pode ignorar a responsabilidade de que, essa continuidade, trata-se de um amadurecimento da dimensão ética de sua orientação. Importa notar também que é nesta continuidade que Gadamer determina aquilo que será essencial na sua própria busca pelo reconhecimento da natureza da verdade que, através da obra de arte, se afirma como exemplar à experiência da compreensão hermenêutica: 
Na medida em que o estágio estético da existência se mostra em si insustentável, reconhece-se que o fenômeno da arte coloca uma tarefa à existência: em face da atualidade arrebatadora de cada impressão estética, alcançar a continuidade da nossa autocompreensão, que é a única capaz de sustentar a existência humana (Dasein). [...] Na verdade, reconhecer a 'caducidade do belo e o caráter aventureiro do artista' não significa uma estruturação ontológica fora da 'fenomenologia hermenêutica' da existência, mas, antes, uma formulação da tarefa de, em face de tal descontinuidade do ser estético e da experiência estética, preservar a continuidade hermenêutica que perfaz o nosso ser. (GADAMER, 2012, p. 147-148/GW1, 101-102)

Ou seja, é assim que a experiência da obra de arte se torna exemplar no problema que pode ser considerado como um dos mais importantes para a hermenêutica filosófica, a saber: a responsabilidade que alguém carrega na formação da orientação que conduz a continuidade hermenêutica que perfaz o ser, especialmente se considerado o desafio que a abertura à alteridade impõe a esta continuidade - porque a verdade somente pode surgir em meio a este jogo. $\mathrm{O}$ aspecto espetacular do belo já é evidenciado aqui em função desta noção de verdade que pertence ao horizonte finito da existência e é referente, nestes termos, à autocompreensão humana. Pode-se perceber, assim, porque para Gadamer "também a experiência estética é uma forma de autocompreender-se" (GADAMER, 2012, p. 149/GW1, 102) - o que torna, em certo sentido, a estética subalterna à hermenêutica - é porque nenhuma perspectiva de experiência se sustentaria numa plena abstração, elas só são tomadas e compreendidas quando continuidade e abertura estão em jogo. Assim,

isso significa que na continuidade da nossa existência suspendemos a descontinuidade e a pontualidade da vivência. Por isso, em relação ao belo e à arte, importa ganhar um horizonte que não busque imediatez, mas que corresponda à realidade histórica do homem. (GADAMER, 2012, p. 149/GW1, 102) 
Sobre a importância do belo para a verdade hermenêutica do ser

Logo, parece legítimo e necessário se questionar como a experiência do belo se integra na "continuidade hermenêutica do ser" considerando a importância desta experiência para a própria determinação da verdade hermenêutica. No intuito de aprofundar a possibilidade desta questão e de trazer à tona a real extensão que Gadamer quer dar a este problema, façamos primeiro uma análise da famosa crítica a Kant que, basicamente, quer afirmar a possibilidade de um conhecimento e uma verdade da arte que está além da estética.

\section{A crítica de Gadamer à autonomia do belo}

Como se sabe, o ponto para o qual Gadamer é discordante em relação a Kant se trata da possível "subjetivação" da estética que teria ocorrido em função da terceira Crítica. A isto liga-se o fato de que os conceitos centrais da tradição humanista ${ }^{1}$, que dariam aporte para uma legitimação própria às humanidades, são reunidos por Kant sem a consideração de todo o significado social e comunitário que a eles seria imanente. A exemplo disso, para Kant "não pode haver nenhuma regra de gosto objetiva que determine através de conceitos o que seja o belo. Pois todo o juízo proveniente desta fonte é estético; isto é, o sentimento do sujeito, e não o conceito de um objeto, é seu fundamento determinante" (KANT, 2012, p. 73). Gadamer, por sua vez, defende que o gosto originariamente possui um cunho voltado essencialmente ao moral, sendo assim um fenômeno social de primeira grandeza, logo, "uma questão básica do gosto, assim, não será só reconhecer como bela esta ou aquela coisa que é efetivamente bela, mas considerar o todo ao qual deve concordar tudo que é belo" (GADAMER, 2012, p. 78/GW1, 43). Nesta perspectiva de Gadamer, bem se vê que ele considerará que a distinção entre o juízo determinante e o juízo reflexivo, na qual está baseada a terceira Crítica, não pode ser uma distinção absoluta, já que o gosto, na medida em que tem de considerar o todo ao qual deve concordar tudo o que é belo, também precisa ser visto como algo que sempre permeia e é permeado pelo juízo ético. Consequentemente, o belo, na perspectiva de Gadamer, nunca está desvinculado de ser uma noção que também se volta para a questão ética.

1Estes conceitos são quatro: Bildung, sensus communis, juízo e gosto; e eles estão reunidos e relacionados na terceira Crítica com base na função transcendental que Kant dá ao juízo de gosto. Como explica Schmidt: "essas noções nomeiam as experiências e ideais que preservam um sentido da verdade não capturado por essas regras do método e a objetificações que fundamentam as ciências naturais e que passaram a determinar - inapropriadamente - as ciências humanas (Geisteswissenschaften). Ao reconhecer uma experiência e uma possibilidade de verdade que não pode ser recuperada pelo método e pelos ideais da ciência, a tradição humanista fornece a base histórica sobre a qual questões da experiência humana e da verdade podem ser recuperadas a partir das ciências humanas" (SCHMIDT, 2007, p. 31). 
Este é o cenário de fundo onde irá se explorar a importância e o sentido que a obra de arte assume neste contexto, sendo que a crítica de Gadamer vai se voltar para o seguinte:

apesar de que Kant vai juntar e cristalizar a unidade dos principais conceitos do humanismo, e apesar de que ele vai reconhecer que o domínio definido por arte bela $[\ldots]$ desempenha uma papel privilegiado em qualquer explicação da unidade destes conceitos, no final, para a vantagem do juízo estético puro, a obra de arte não contribui nada para o que é revelado (SCHMIDT, 2007, p. 32).

São duas as observações necessárias aqui: primeiramente, não sendo o belo na obra de arte uma beleza livre (pulchritudo vaga), ou seja, uma beleza que "não pressupõe nenhum conceito do que o objeto deva ser", mas sim uma beleza aderente (pulchritudo adhaerens) que pressupõe a perfeição do objeto sob determinado conceito, na interpretação de Gadamer, Kant teria reduzido o real problema da arte, em função de favorecer o juízo de gosto puro, ao se esquivar da questão do conteúdo que a obra de arte carrega em si e que não poderia, de modo algum, encontrar consenso ou mediação com aquela beleza vaga que é a única capaz de justificar a fundamentação transcendental que Kant dá ao juízo estético. A escapatória estaria em simplesmente afirmar que o belo reside na forma e tão somente na forma, não sendo possível adentrar em um sentido mais específico do que isto seja. Em segundo lugar, sob esta perspectiva terá que se perceber que é o conceito de belo que concentra a finalidade da crítica de Gadamer e, não menos do que isto, é a própria ressignificação da real dimensão na qual este conceito pode e deve inserir-se. Isto quer dizer que a experiência de beleza que é revelada pela obra de arte não é destituída de um conteúdo que a sustém, sendo em função disso - já é possível adiantar - que Gadamer desenvolve a sua ontologia da obra de arte.

Todavia, apesar da crítica de Gadamer a Kant ser bastante estigmatizada como uma crítica de cunho "negativo" - quer dizer, que busca pelo contra-modelo da teoria do juízo estético - existe, pelo menos, um ponto onde é claro o elogio a Kant e, que apesar disso, é o ponto onde sua crítica expõe o seu propósito. Pela centralidade desta questão, tanto para se fazer entender a crítica de Gadamer quanto para o objetivo de minha análise, concentrarei a minha análise neste ponto. Este se refere ao fato de que Gadamer entende que a verdadeira 
importância da teoria kantiana do ideal da beleza, que assume que "um ideal da beleza só existe com relação à figura humana: na 'expressão do ético', 'sem a qual o objeto não agradaria de forma universal"' (GADAMER, 2012, p. 88-89/ GW1, 54), seria que neste ponto da terceira Crítica já estaria sendo preparado a determinação da essência da arte que consistiria em "confrontar o homem consigo mesmo". Vejamos a questão mais acuradamente.

O $\$ 17$ da terceira Crítica - "Do ideal da beleza" - é central para o problema do belo. Kant diz que "o modelo mais elevado, o original do gosto é uma simples ideia que cada um tem de produzir em si próprio e segundo a qual ele tem de ajuizar tudo o que é objeto de gosto" (KANT, 2012, p. 74); neste contexto, a beleza em seu ideal não está vinculada ao juízo de gosto puro, pois não se trata aqui de uma beleza vaga, mas de "uma beleza fixada por um conceito de conformidade a fins objetiva; consequentemente não tem de pertencer a nenhum objeto de gosto totalmente puro, mas ao de um juízo de gosto em parte intelectualizado" (KANT, 2012, p. 75). A própria possibilidade de uma teoria de um ideal da beleza está na distinção que Kant faz de uma "ideia normal" e uma "ideia racional"; onde a primeira refere-se apenas ao fato de que a sua representação agrada por não contradizer nenhuma das condições sob as quais um objeto pode ser belo, ou seja, é a forma que permite a correção da espécie; e onde a segunda "faz dos fins da humanidade, na medida em que não podem ser representados sensivelmente, o princípio de ajuizamento de sua figura" (KANT, 2012, p. 76). A figura humana é a única que permitiria as duas ideias, porque é unicamente nela que existe um ideal de beleza (ideia racional) e que consiste em ser a "expressão do moral". Kant conclui o parágrafo dizendo que "o ajuizamento segundo um tal padrão de medida jamais pode ser puramente estético e o ajuizamento segundo um tal ideal de beleza não é nenhum simples juízo de gosto" (KANT, 2012, p. 79).

Gadamer pensa que, pelo fato deste ideal de beleza consistir na "expressão do ético", se este momento da terceira Crítica já for visto como um presságio da futura teoria das ideias estéticas e da beleza como um símbolo da moralidade, então, já se encontra aqui aquilo que pode ser considerado a essência da arte - confrontar o homem consigo mesmo -; porque "na representação da figura humana o objeto representado e aquilo que fala nessa representação como conteúdo artístico são a mesma coisa. [...] o prazer intelectualizado e interessado nesse ideal representado da beleza não se separa do prazer estético mas torna-se uno com ele" (GADAMER, 2012, p. 90). Vale lembrar que isto tem que estar ligado àquela distinção, anteriormente exposta, entre beleza livre e beleza aderente, onde esta segunda teria gerado na teoria kantiana a possibilidade da 
discussão do belo na arte. Hamm chama a atenção para o fato de que "a função desta distinção não consiste [...] na marcação da diferença entre o belo natural e o belo da arte e na priorização do primeiro [...] mas apenas na acentuação da independência sistemática do belo de qualquer conceito determinante ou determinado" (HAMM, 1998, p. 16), o que quer dizer que, em última análise, a beleza só pode existir naqueles casos em que a imaginação e o entendimento estão em livre jogo. Como o ideal da beleza pertence ao caso de uma beleza aderente, sendo que a perfeição em questão aqui parece ser a própria noção de humanidade (já que é somente o homem que pode determinar seus fins pela razão), Gadamer pensa ser possível que, nestes termos, ética e estética confluam a um mesmo ponto. O que Hamm novamente observa é que justamente isto - "essa fusão intelectual-moral ('interessado') com o prazer estético ('desinteressado') - que [...] não é mais o resultado de uma operação kantiana, mas gadameriana - abre definitivamente o caminho para uma interpretação da estética kantiana mais sob o ponto de vista da arte" (HAMM, 1998, p. 19) - o que é de todo essencial para Gadamer e que em Kant parece estar, na melhor das hipóteses, evidentemente sugerido. Em todo caso, não há dúvida de que o juízo de gosto puro, em vistas apenas do belo natural, é tão restritivo que as possibilidades de alguma aplicação mais ampla do juízo estético deveria de ser almejada por Kant. Zammito (1992), por exemplo, entende que é a noção de perfeição ligada à beleza aderente que está por trás disto, e que, na medida em que a beleza só pode ser um ideal da imaginação, a ideia racional estaria em função de abarcar a perfeição de um caso de beleza aderente; assim, “o 'ideal da beleza' como o 'modelo mais elevado' poderia ser o esquema implícito com o qual o juízo compara qualquer instância particular para discernir se está é bela ou não" (ZAMMITO, 1992, p. 128). Desta forma, também é possível considerar que

uma ideia normal estética, apesar de interessante, só oferece uma linguagem diferente para formular o que Kant tinha explicado mais claramente ao relacionar o juízo de gosto à harmonia das faculdades. Isto não faz de modo algum avançar a nossa compreensão de como o juízo de gosto pode ser alargado a objetos mais complexos, particularmente aqueles que parecem implicar um propósito intrínseco e, portanto, não faz avançar a nossa compreensão da pulchritudo adhaerens como uma questão estética (ZAMMITO, 1992, p. 128-129). 
É esta dificuldade da teoria estética kantiana que Gadamer quer assumir e levar a cabo em sua possibilidade hermenêutica. Por fim, o que caracteriza a sua análise é o fato dele pensar que já em Kant estaria exposto que a beleza alcança a sua verdadeira profundidade onde a imaginação pode ser produtiva, mas, nesse caso, o seu verdadeiro potencial não seria alcançado onde a imaginação é simplesmente livre, mas "onde vive um espaço de jogo que instaura o empenho compreensivo por unidade, não como barreira mas prelineando estímulos para seu jogo" (GADAMER, 2012, p. 88/GW1, 52); e desta forma - quando chama a atenção de que "somente da figura humana, justamente por ser a única capaz de uma beleza fixada por um conceito teleológico, existe um ideal de beleza" (GADAMER, 2012, p. 89/GW1, 53), que consiste na expressão do moral - Gadamer quer mostrar que este é, na verdade, um "grande salto" no pensamento da arte ocidental (que naquele momento via-se dominado pela estética sensualista e racionalista, e pela ideia do fundamento da arte como a imitação da natureza) e fazer reconhecer que

Kant destrói o fundamento a partir da qual a estética da perfeição encontra a sua beleza única e incomparável na plena agradabilidade sensorial de todo ente. Somente então a arte consegue se tornar um fenômeno autônomo. Sua tarefa não é mais a representação do ideal da natureza, mas o encontro do homem consigo mesmo na natureza e no mundo humano-histórico (GADAMER, 2012, p. 91/GW1, 55).

É, pois, este "encontro" do homem consigo mesmo que é preciso ser entendido como um propósito fundamental que Gadamer visa com a sua hermenêutica. No entanto, as últimas consequências desta possibilidade aberta por Kant não serão por este exploradas, e a isto está ligado o fato de que Kant pensa que a importância do belo é distinta no caso da natureza e da arte, e vê, decididamente, que o belo da arte "não fornece absolutamente nenhuma prova de uma maneira de pensar afeiçoada ao moralmente bom ou sequer inclinada a ele" (KANT, 2012, p. 153), é apenas à beleza da natureza que convém um interesse imediato. Como Gadamer explica, isso significa que "na medida em que [Kant] percebe a coincidência não intencional da natureza com o nosso prazer, [...] esse interesse aponta-nos como o fim último da criação, a nossa 'determinação moral"' (GADAMER, 2012, p. 93/GW1, 56). Por fim, é desta forma que Kant 
Sobre a importância do belo para a verdade hermenêutica do ser
Mndo. Danton Guilherme Oestreich [CAPES | Unisinos]

admite que o sentimento ético seja aguçado apenas pelo belo natural e não pela arte. É justamente aqui que se estabelece a contraposição mais importante de Gadamer a Kant:

Com vistas à ideia de uma determinação inteligível da humanidade, a natureza enquanto bela natureza ganha uma linguagem que a conduz a nós. É claro que a importância da arte repousa também no fato de nos interpelar, e de colocar o homem diante de si mesmo em sua existência determinada moralmente. Mas os produtos artísticos só servem para nos interpelar; os objetos naturais, ao contrário, não estão aí para nos interpelar. Justamente nisso consiste o significativo interesse pelo belo natural, que, não obstante isso, consegue tornar consciente nossa determinação moral. A arte não pode nos proporcionar esse encontro do homem consigo mesmo numa realidade não intencional [...]. Em si, isso está correto. Mas por mais interessante que seja a probidade do seu raciocínio, Kant não coloca o fenômeno da arte sob um padrão a ela adequado. [...] podemos constatar [...] a vantagem da arte sobre o belo natural no fato de que a linguagem da arte é uma linguagem exigente e interpeladora. A arte não se oferece livre e indeterminada à interpretação que vem da disposição de ânimo, mas nos interpela com significados bem determinados. E o que há de misterioso e maravilhoso na arte é que esta interpelação determinada não representa um grilhão para o nosso ânimo, mas justamente abre o espaço de jogo da liberdade lúdica de nossa capacidade de conhecimento. (GADAMER, 2012, p. 93-94/GW1, 57)

É sob a luz desta perspectiva que se pode compreender no que consiste a diferença do conceito de jogo livre em seu nível estético, e o jogo como o próprio modo de ser da obra de arte em nível ontológico, pelo qual Gadamer parece se "contrapor" à teoria kantiana. Dizendo de modo mais específico, isto quer dizer que a compreensão na experiência da obra de arte joga não apenas com as faculdades de conhecimento, de modo puro ou simplesmente formal, mas que ela é sempre orientada por uma significabilidade prévia que é diretriz para a "leitura" do sentido que está, assim, em jogo com a obra. Esta significabilidade pertence ao 
próprio horizonte finito e histórico do ente, o que, dito de outro modo, pertence à formação da sua continuidade hermenêutica. O que realmente interessa perceber na concepção de jogo de Gadamer é isto, que tão bem descreve Eugen Fink:

o homem é habitado pelo pensamento da imensidão e do infinito, vive na agitação do universo, à sombra da morte, nas fadigas do trabalho, nas querelas pela dominação, na felicidade frágil do amor, no jogo que representa. Talvez a mediação sobre o jogo siga um fio que não conduz para fora do labirinto do questionamento, mas, ao contrário, aí nos aprofunda mais profundamente (ROHDEN, 2002, p. 113).

É preciso notar é que nesta concepção de jogo a possibilidade do sentido depende da consciência do horizonte hermenêutico do ser e pauta-se fundamentalmente no conhecimento que a autocompreensão alcança em relação a própria existência humana. Assim, não é demais afirmar que é apenas na experiência hermenêutica que a compreensão da arte tem o seu lugar próprio, e que fora desta compreensão a arte é apenas considerada parcialmente, sendo esta a razão pela qual Gadamer pensa ser necessário ir além das considerações estéticas para uma justa perspectiva do sentido da arte.

Por outro lado, é preciso chamar atenção para o fato de que isto que pode ser chamado de "jogo hermenêutico" na arte não é essencialmente diferente daquilo que Kant chama de "jogo livre"; na verdade, o jogo enquanto modelo ontológico da obra de arte não nega o jogo livre como modelo ideal da estética, embora tampouco tenham que ser coexistentes. O que realmente ocorre é que, se para Kant o que faz perceber o belo é a correspondência harmônica entre a imaginação e o entendimento, quando estas faculdades estão como que em um livre jogo entre si (algo que consiste basicamente no ajuizamento de questões formais para o reconhecimento da beleza), a pergunta pelo que a arte nos comunica não é desenvolvida por Kant; já para Gadamer essa pergunta é essencial e não pode ser colocada em segundo plano quando falamos da beleza na arte. Desta forma, a diferença entre ambos está no fato de que o jogo livre é uma relação idônea do juízo estético que reconhece o belo, sem perguntar pelo conteúdo do objeto artístico; enquanto no jogo ontológico-hermenêutico se dá uma interpelação de sentido que ocorre a partir do conteúdo que se pode reconhecer na obra de arte, conteúdo que tem o seu lugar próprio na continuidade hermenêutica do ser. 
Sobre a importância do belo para a verdade hermenêutica do ser

Provavelmente o exemplo mais extremo, que pode ser apresentado para ilustrar essa questão, é o exemplo da noção de "música absoluta"2. Embora tal noção tenha emancipado a arte musical de qualquer função representativa, em favor de afirmar que o conteúdo da música é a beleza da sua pura resolução formal em termos de combinações sonoras, também neste caso é preciso se considerar que existe um horizonte de sentido e significado que é essencial para a "leitura" de tal experiência. Gadamer mesmo diz que "embora a música absoluta seja, como tal, um pura mobilidade da forma [...] o entender mantém uma referência para com o que é significativo" (GADAMER, 2012, p. 142-143/ GW1, 97); e - apesar desta referência ser na música absoluta de certo modo "indeterminada" - a pretensão de expressar beleza através da pura combinação formal dos sons é algo significativo para a compreensão do horizonte de sentido deste tipo de arte musical. Ora, a questão é que sem a consciência deste significado, que sustém o propósito da experiência artística da música absoluta, corremos o risco de perder ou, ao menos, alterar substancialmente a possibilidade de compreensão de uma tal pretensão de beleza. O que se deve reconhecer é que, com o conceito de jogo, Gadamer quer pensar como é possível a beleza enquanto algo que não tem a sua existência simplesmente com base numa abstração de uma autonomia que lhe seria própria.

Se Gadamer se contrapõe realmente à uma determinada perspectiva de jogo livre, esta seria aquela perspectiva radical que Schiller apresenta em $A$ educação estética do homem, onde "numa obra de arte verdadeiramente bela o conteúdo não deve nada fazer, a forma tudo; é somente pela forma que se atua sobre o todo do homem" (SCHILLER, 2001, p. 107), porque o conteúdo é sempre uma limitação do espírito. Naturalmente, a perspectiva de Gadamer sobre o assunto é exatamente a inversa: a limitação do espírito sempre existe, tem por seu fundamento o seu conteúdo e, mesmo assim, nada disto lhe impede a experiência de beleza, pelo contrário, tanto

2 Durante o século XIX, como resultado direto da consolidação da estética como horizonte de reflexão própria da arte, a música instrumental alcançou o estatuto de bela arte pela sua emancipação de qualquer necessidade representativa. A beleza estaria na própria forma musical e tão somente nela - a isto se designa "música absoluta" - noção ligada à ideia de uma beleza e de uma arte autônoma. Vale notar que a prática musical que possibilitou e promoveu tal noção estética antecede bastante esta discussão (ela é oriunda do final do século XVIII, me refiro a prática composicional da forma sonata clássica). De todo modo, a obra que marca o início dessas reflexões como uma questão estética da música é Do belo musical de Eduard Hanslisk, publicada em 1854 em Viena, que advoga "um belo que, sem depender e sem necessitar de um conteúdo exterior, consiste unicamente nos sons e em sua ligação artística" (HANSLICK, 1992, p. 61). Curiosamente, Kant que tão pouco se interessou pela música, como uma arte bela, criou a base teórica que permitiu a música se elevar ao posto da maior das artes no romantismo, enquanto caracterizada por ser capaz de expressar o inefável. 


\begin{abstract}
o belo quanto o acontecer hermenêutico pressupõem fundamentalmente a finitude da existência humana. Podemos inclusive perguntar se um espírito infinito poderia experimentar o belo como nós o experimentamos. Poderia ele ver outra coisa que a beleza do todo que tem diante de si? O 'aparecer' do belo parece reservado à experiência humana finita (GADAMER, 2012, p. 626, GW1, 489).
\end{abstract}

O todo que é referente à experiência humana não é nada se for visto apenas através de uma consideração formal, porque é necessário admitir que na obra de arte "a mensagem é mais do que o meio, e uma estrita "autonomia da arte" formalista só pode ser comprada com o custo de sua trivialidade absoluta" (ZAMMITO, 1992, p. 290); logo, isto é o mesmo que dizer que sob uma perspectiva simplesmente formal, se perdem todas as referências de sentido que promovem a ideia da beleza e que permitem a continuidade de sua consideração. Dizendo de outro modo, a beleza pode ser considerada o "objeto" do impulso lúdico, mas o sentido do impulso lúdico nunca pode ser absolutamente desvinculado daquilo que nos constitui enquanto finitude e historicidade; sendo assim, para fazer jus à singular experiência de sentido que encontramos através do jogo, é mais apropriado considerar que "no comportamento lúdico não desaparecem simplesmente todas as referências à finalidade que determinam a existência atuante e cuidadosa, mas, de uma forma muito peculiar, permanecem em suspenso" (GADAMER, 2012, p. 54/GW1, 107). É por isso que Gadamer insiste em argumentar que o jogo da arte trata-se de uma genuína experiência em que o sujeito é "levado" pelo jogo, quer dizer, onde a subjetividade é suspensa. Talvez seria melhor abordar a questão da subjetividade na arte não de um modo tão radical, como faz Gadamer, e simplesmente expor, como sugere Kelly (2004), uma noção de subjetividade mais ampla; em todo caso, mesmo desta forma o resultado da proposta de questões hermenêuticas para a arte seria o mesmo: Gadamer "está interessado em uma subjetividade historicamente situada em vez de uma subjetividade abstrata, alienada na forma da consciência estética [...]. Com efeito, ele visa recontextualizar a arte autônoma" (KELLY, 2004, p. 116); e por meio desta recontextualização abrir questões mais amplas relativas à experiência da beleza e da verdade. 


\section{A importância do belo para a autocompreensão humana}

Antes de retomar a questão deixada ao final da primeira seção deste artigo, é importante colocar em evidência a principal diferença que vem a caracterizar a hermenêutica de Gadamer em relação à Hermenêutica da faticidade de Heidegger, que, assumidamente, pode ser considerada como o "ponto de partida" da reflexão hermenêutica de Gadamer.

$\mathrm{O}$ fundamento da investigação e abordagem hermenêutica em Verdade e Método é a busca de um aprofundamento do fenômeno da compreensão. É a concepção hermenêutica de Heidegger que teria aberto novos rumos para este aprofundamento, pois, nela, a compreensão não limita-se a uma teoria da interpretação; trata-se da "autointerpretação da faticidade", o quer dizer que "na hermenêutica configura-se ao ser-aí como uma possibilidade de vir a compreender-se e de ser essa compreensão" (HEIDEGGER, 2013, p. 21). O que Gadamer assume da filosofia de Heidegger como algo fundamental para o seu próprio projeto filosófico está ligado ao fato de que "a nova redução da filosofia às experiências básicas da existência humana que era preciso explicitar" (GADAMER, 2002, p. 550/GW2, 483); mas, por outro lado, uma diferença marcante que assinala a sua perspectiva é que "enquanto Heidegger tinha projetado em sua antiga preleção a filosofia como a possibilidade de o ser-aí 'vir a ser e ser para si mesmo de maneira compreensiva', o que está em questão para Gadamer é transformar o ser-previamente-dado do ser histórico na 'base ontológica' do pensamento filosófico" (FIGAL, 2007, p. 24). Sendo assim, neste contexto o problema da compreensão, re-orientado a partir da existência humana, coloca a pergunta sobre o que caracteriza a experiência da verdade enquanto atrelada à experiência da finitude e da historicidade sendo que, como foi visto, mesmo a arte e o belo pertencem a este horizonte. Por isso, quando Gadamer começou a elaborar a sua hermenêutica filosófica percebeu que, ainda que o seu ponto de partida deveria ser as "ciências da compreensão", a experiência da arte teria que ser um complemento necessário, mesmo que até então não havia sido levada em consideração dentro deste problema. Esta necessidade se pautaria no fato de que "a arte e as ciências históricas são modos de experiência que implicam diretamente nossa própria compreensão da existência (Daseinsverständnis unmittelbar ins Spiel kommt)" (GADAMER, 2002, p. 564-565/GW2, 495). Assim, se Heidegger, no caso de $A$ origem da obra de arte, conduz seu questionamento em função de revelar o originário da arte, onde a verdade como desvelamento surge como resposta para este problema como um acontecer poético-apropriante da verdade, para o questionamento de Gadamer a verdade que será discutida na arte não pode desvencilhar-se do horizonte da compreensão hermenêutica do ser. 
Sobre a importância do belo para a verdade hermenêutica do ser

Como foi visto também, por Gadamer considerar a verdade do ser através de uma perspectiva hermenêutica, acaba conduzindo-a e inserindo-a de modo bastante determinado na dimensão da compreensão que ocorre através da linguagem, em amplo sentido. Por isso, é possível encontrar, de sua parte, afirmações bastante específicas sobre como a verdade se dá no contexto hermenêutico; por exemplo:

Se quisermos apreender um enunciado em sua verdade, não podemos levar em conta apenas o conteúdo que ele apresenta. Todo enunciado tem uma motivação. Todo enunciado tem pressupostos que ele não enuncia. Somente quem pensa também esses pressupostos pode dimensionar realmente a verdade de um enunciado. Ora, afirmo que a última forma lógica dessa motivação de todo enunciado é a pergunta. Não é o juízo mas a pergunta que tem o primado na lógica [...]. O primado da pergunta frente ao enunciado significa, porém, que o enunciado é essencialmente resposta. Assim, não pode haver compreensão de um enunciado, se essa não se pautar unicamente na compreensão da pergunta a que o enunciado responde. (GADAMER, 2002, p. 66-67/GW2, 52)

Gadamer está aprofundando, a seu modo, aquilo que na Hermenêutica da faticidade já aparece como uma das características fundamentais da compreensão - a de que toda possibilidade de ser está ligada a uma questionabilidade fundamental. Nas palavras do próprio Heidegger: "na questionabilidade e somente nela alguém pode assumir a posição na qual se dá e para a qual se dá algo a que se pode chamar pelo termo 'fixo"' (HEIDEGGER, 2013, p. 23). Devo salientar a importância deste ponto, pois não é por acaso que as últimas palavras de Verdade e Método são as seguintes: 'O que o instrumental do 'método' não consegue alcançar deve e pode realmente ser alcançado por uma disciplina do perguntar e do investigar que garante a verdade" (GADAMER, 2012, p. 631/ GW1, 494). Este compromisso último que a obra coloca no horizonte do pensamento hermenêutico, pode ser seguido, sem dúvida, de considerações das mais difíceis com as quais o homem deve e pode lidar em sua existência; a exemplo disso, afirma Rohden: - "a metafísica implícita na hermenêutica filosófica é que o homem - enquanto ser de linguagem, ao filosofar - assume a inesgotável 
Mndo. Danton Guilherme Oestreich [CAPES | Unisinos]

tarefa de poder perguntar e dever perguntar para além de todas as respostas alcançáveis enquanto totalidade impossível de ser totalmente tematizada" (ROHDEN, 2002, p. 288). Nesta experiência é o horizonte hermenêutico do ser que coloca as relações de sentido que alguém assume como possíveis através da sua própria capacidade de compreensão da existência, relações estas que estão na "continuidade hermenêutica que perfaz o nosso ser" e que, ao permanecerem sempre em jogo diante das novas experiências, são o ponto primeiro para o reconhecimento daquilo que forma a nossa orientação no mundo.

É isto que quero, por fim, evidenciar: aquilo que pode ser chamado por "a verdade hermenêutica do ser", enquanto é algo que implica sua dependência à consciência da finitude e da historicidade que a sustém, está relacionada com a autocompreensão na experiência da existência humana; e, na medida em que a existência somente adquire sentido a partir da continuidade hermenêutica do ser, existe um compromisso ético implícito na formação da continuidade que possibilita a compreensão da existência. Este compromisso, por sua vez, recai no modo como ambicionamos e conduzimos a nossa autocompreensão através dos questionamentos que pautam a nossa busca de compreensão sobre a existência. Nesse sentido, a verdade que realmente importa para a hermenêutica não é qualquer experiência de verdade, mas é aquela experiência que alivia, em um dado momento, o nosso anseio por respostas que satisfaçam a nossa dúvida existencial.

Ao rememorar o significado do belo na filosofia antiga, em que este conceito fazia parte essencial da metafísica, Gadamer diz que "chama-se kalon tudo o que não faz parte das necessidades da vida, mas que diz respeito ao modo como se vive" (GADAMER, 2012, p. 616/GW1, 481); ora, isto faz parte do ethos que determina um comportamento perante a valoração da vida. Quando se está a falar de uma "continuidade hermenêutica que perfaz o nosso ser" não há dúvida de que se está a falar de algo que caracteriza o modo como vivemos - e isto pauta a consciência crítica que nos determina perante a capacidade de reconhecimento de algum sentido que está em jogo no ato da compreensão. Neste sentido, seria até mesmo possível afirmar que a autocompreensão é também uma experiência de beleza porque ela também se caracteriza não por ser algo referente às "necessidades básicas" da vida, no sentido elementar da nossa existência biológica, mas sim por dizer respeito à forma de vida pela qual orientamos a nossa existência espiritual.

Gadamer parece considerar o resultado da sua investigação sobre a compreensão no seguinte trecho, da última página de Verdade e Método, que de certa forma sintetiza aquilo que a obra visa mostar: 
Aquele que compreende já está sempre incluído num acontecimento, em virtude do qual aquilo que possui sentido acaba se impondo. Assim, é com razão que se emprega o mesmo conceito de jogo tanto para o fenômeno hermenêutico quanto para a experiência do belo. Quando compreendemos um texto, nos vemos tão atraídos por sua plenitude de sentido como pelo belo. Ele ganha validez e já sempre nos atraiu para si, antes mesmo que alguém caia em si e possa examinar a pretensão de sentido que o interpela. O que nos vem ao encontro na experiência do belo e na compreensão do sentido da tradição tem realmente algo da verdade do jogo. (GADAMER, 2012, p. 631/GW1, 494)

De todo modo, parece que busca pela pergunta que orienta a compreensão ainda assim permanece sendo como uma tarefa do sujeito e, na medida em que deve se transformar numa "disciplina", ela também subentende um modo de comprometimento ético da parte deste. Sendo assim, a verdade hermenêutica do ser é um sentido que acontece em vista de um questionamento que orienta as possibilidades da (auto)compreensão do ente. Seria possível argumentar, com base nisso, que a tarefa que a hermenêutica coloca para a compreensão em sua situação fática trata-se sempre de um desafio bastante específico - o de trazer à tona a questionabilidade fundamental que orienta a compreensão do sentido que ilumina a existência humana. Mas, não se trata, então, de um desafio um tanto limítrofe para a autocompreensão? Para Heidegger, a primeira de todas as perguntas é esta: "Por que existe em geral o ente e não antes o nada?" (SHIMABUKURO, 2014, p. 100); isto porque esta é a pergunta que permite a abertura da experiência do ser e a sua respectiva verdade. Gadamer parece querer estender o horizonte do questionamento humano, que deve ser considerado também como essencial, para todo "o amplo oceano do belo que se alastra na realidade ética do homem", onde a verdade vigora quando diz respeito ao sentido capaz de iluminar a nossa compreensão e que, em nossa condição finita, só pode ser conservado como um modo de continuidade hermenêutica.

Esta autocompreensão de que trata a hermenêutica filosófica não se refere à busca de certezas, mas sim à possibilidade de uma valoração da própria vida humana. O belo é de suma importância aqui porque a genuína compreensão hermenêutica refere-se sobretudo à busca do reconhecimento de algum sentido que seja harmônico com tudo o que pode ser considerado belo no horizonte da 
existência. Parece ser este o ponto para o qual Gadamer quer chamar atenção ao final de Verdade e Método, e que justifica a inserção do conceito de belo a esta altura da obra. Assim, se a hermenêutica se expressa com a perspectiva de que a compreensão é um acontecimento que ocorre na tradição, e de que as possibilidades do sentido de algo já a pertencem, isso mostra que o belo pode ser considerado como aquilo que na tradição é o mais próprio de uma existência plena; no entanto, na medida em que esta plenitude só pode ser "calculada" em vista da experiência de finitude que caracteriza o humano, o belo é também uma experiência formativa e implica, assim, o nosso comprometimento ético.

\section{Considerações finais}

Sem dúvida, a questão da importância do belo no contemporâneo é uma questão difícil de ser creditada, mas a hermenêutica filosófica pretende mostrar que ela convém sobretudo para a vida humana em seu aspecto de ter sentido e sentir seu valor em nossa historicidade. Uma perspectiva de sentido para a vida não pode se reduzir e nem ser expressa pelo conceito, mas como o nosso relacionamento compreensivo com este sentido continua sendo mediado pela nossa capacidade de linguagem, é essencial que este sentido encontre formas outras de apresentação, compreensão e cultivo.

É por isso que a experiência da obra de arte é tão importante neste horizonte, pois a arte é uma linguagem na medida em que é capaz de comunicar algo e, de fato, ela é capaz. Aquilo que ela comunica, no entanto, parece não se reduzir a qualquer sentido que possa findar uma reflexão sobre determinado assunto, pelo contrário, encontramos nela um sentido que sempre volta a enriquecer e aprofundar a nossa capacidade de consideração da verdadeira amplidão do universo hermenêutico humano. As perguntas da arte são perguntas relacionadas ao amor, à morte, às experiências de transcendência do humano, entre tantas outras; e nisto a experiência da arte parece colocar à prova a nossa capacidade da compreensão pelo fato da reflexão do seu questionamento sempre escapar de qualquer resposta simples, determinada e reducionista. Quero dizer com isso que obras de arte são criadas em função de uma tentativa de expressão e de comunicação de sentidos que ultrapassam evidentemente qualquer redução conceitual, mas, que mesmo assim, ainda pertencem a nossa possibilidade de compreensão e conhecimento; é por isso que Gadamer pode afirmar que "todo encontro com a linguagem da arte é um encontro com um acontecimento inacabado" (GADAMER, 2012, p. 151/GW1, 105). A nossa capacidade de reconhecer perguntas 
que orientam a existência de determinado ente - mesmo aqueles dotados de uma linguagem tão peculiar, como as obras de arte - é o que ocupa a hermenêutica filosófica de uma tarefa especial. Trazer à tona a questionabilidade fundamental que orienta a compreensão do sentido da obra de arte é o próprio jogo da arte, e é assim que o jogo da arte acaba se referindo a algo da existência humana que é muito maior. Por isso, o valor do sentido que encontramos com a arte tem que ser correspondente às experiências de compreensão da existência humana, onde a experiência de beleza também diz respeito à nossa condição e, nisso, prova ser uma fonte inestimável de autocompreensão ética da existência.

É importante perceber que a determinidade de um horizonte de sentido também deve ser entendida como uma forma de auto-limitação, ou seja, em contrapartida a ênfase de discurso da hermenêutica a uma eterna necessidade de abertura do ser, nunca se deve relegar que a própria possibilidade de experiência é uma possibilidade de finitude à qual nos condicionamos. É claro que Gadamer parece dar autonomia plena à própria experiência e, consequentemente, retirar o papel de escolha que cabe ao sujeito na condução de sua experiência compreensiva; afinal, na autêntica experiência é o sujeito quem é conduzido. Mas penso que em seu discurso pode ser reconhecido, pelo menos implicitamente, a necessidade de uma conduta ética na disciplina do perguntar, que esteja em busca da formação da nossa familiaridade com as experiências do mundo e da vida. É o conceito de belo que se eleva como guia neste horizonte e que serve de modelo para a verdade hermenêutica do ser.

Recebido em: 27.03.2015 | Aprovado em: 06.06.2015

FIGAL, Günter. Oposicionalidade: o elemento hermenêutico e a filosofia. Petrópolis, RJ: Vozes, 2007.

The doing of the thing itself: Gadamer's Hermeneutic Ontology of Language. In: DOSTAL, Robert J. (ed.). The Cambridge Companion to Gadamer. Cambridge University Press, p. 102-125, 2002.

GADAMER., Hans-Georg. Verdade e Método I: traços fundamentais de uma hermenêutica filosófica. 12. ed. Petrópolis, RJ: Vozes; Bragança Paulista, SP: Editora Universitária São Francisco, 2012. Verdade e Método II: complementos e índice.

Petrópolis, RJ: Vozes, 2002. Referência Bibliográfica Para introdução. In: MOOSBURGER, Laura. 2007. "A origem da obra de arte" de Martin Heidegger: tradução, comentários e notas. Curitiba, PR. 158 f. Dissertação (Mestrado em Filosofia). UFPR. p. 66-79.

HAMM, Christian. Gadamer, leitor de Kant: a "experiência estética" vs. "experiência da arte". Studia Kantiana, vol. 1, no. 1, p. 9-28, 1998.

HANSLICK, Eduard. Do belo musical. 2. ed. Campinas, SP: Editora da UNICAMP, 1992.

HEIDEGGER, Martin. A origem da obra de arte. São Paulo: Edições 70, 2010. 
.Hermenêutica da faticidade. Petrópolis, RJ:

Vozes, 2013.

KANT, Immanuel. Crítica da faculdade do juízo. 3. ed.

Rio de Janeiro: Forense Universitária, 2012.

KELLY, Michael. A Critique of Gadamer's Aesthetics.

In: KRAJEWSKI, Bruce (ed.). Gadamer's repercussions: reconsidering the philosophical hermeneutics. University of California Press, p. 103-120, 2004.

ROHDEN, Luiz. Hermenêutica Filosófica: entre a linguagem da experiência e a experiência da linguagem. São Leopoldo, RS: Editora Unisinos, 2002.

SALLIS, John. The Hermeneutics of the Artwork. In: FIGAL, Günter (Hg). Wahrheit und Methode. Berlin: Akademie Verlang, p. 46-57, 2007.

SCHILLER, Friedrich. A educação estética do homem. São Paulo: Iluminuras, 2011.

SCHMIDT, Dennis J. Aesthetics and Subjectivity. In: FIGAL, Günter (Hg). Wahrheit und Methode. Berlin: Akademie Verlang, p. 29-43, 2007.

SHIMABUKURO, Felipe. Arte, filosofia e verdade no pensamento de Heidegger. Ekstasis, vol. 3, no. 1, p. 78108, 2014.

ZAMMITO, John H. The genesis of Kant's Critique of Judgment. Chicago \& London: The University of Chicago Press, 1992.

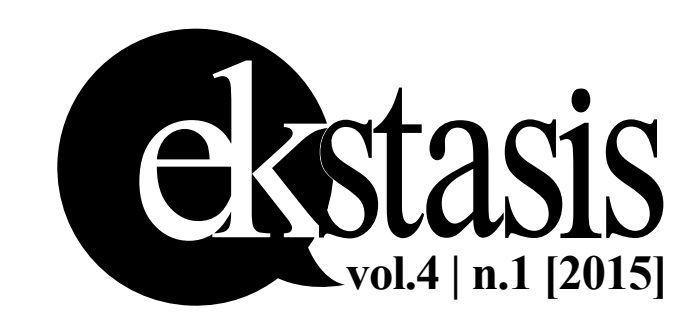

